\title{
Zeolites as Functional Materials for Energy Technology
}

\author{
Hoi-Wun LUI, Frank Leung-Yuk LAM, and Xijun HU* \\ Department of Chemical and Biological Engineering, Hong Kong University of Science and \\ Technology, Hong Kong
}

*Corresponding author: Xijun Hu, Department of Chemical and Biological Engineering, Hong Kong University of Science and Technology, Clear Water Bay, Kowloon, Hong Kong,

\section{Review Article}

Volume 3 Issue 3

Received Date: July 02, 2018

Published Date: July 17, 2018

DOI: $10.23880 /$ nnoa- 16000143

Tel: 2358 7134; Email: kexhu@ust.hk

\section{Abstract}

Zeolites are solids with infinitely extending three-dimensional frameworks of alumina and silica tetrahedra. They first appeared in an academic journal published by Axel Fredick Cronstedt in 1756 . However, the zeolite chemistry was halted for almost 200 years as natural zeolites were so rare, until large-scale industrial production was invented by Richard Barrer in 1930-40s. Ever since then, zeolites have been intensively studied by researchers on their special structures and properties. The discovery of molecular sieve property of zeolite was of vital importance. It allows zeolites to have wide range of applications. Zeolites started to be involved in the energy field in the last two decades. In this paper, the role of zeolites in biofuel and direct methanol fuel cell would be reviewed.

Keywords: Zeolites; Molecular Sieve; Energy; Biofuel; Direct Methanol Fuel Cell; History

\section{An Overview of Zeolite}

Owning to the unique properties, zeolites are widely employed in different applications. Some common known examples are absorbents, catalysts, detergents, and petrochemicals. According to research companies' forecast, in the coming future, the zeolite market for industrial application would persist positive growth [1-3], and even reach USD 33.80 billion by 2022 [4].

Zeolites are natural products of volcanoes erupt and formed while the hot, molten lava and thick ash emitted and flowed into sea, and then interacted with salts in water. The natural zeolites are crystalline solids. The first zeolite in human history was discovered by a Swedish mineralogist, Axel Fredick Cronstedt, in $1756[5,6]$. However, for more than 200 years even since the first zeolite was discovered, zeolites were considered as rare materials due to their abundance and difficulties in separation, zeolites were just for laboratory used. Until 1950s, synthetic zeolites were first created. By this means, zeolites can be manufactured in large-scale and would nolong be limited to laboratory used.

The structure of zeolites is one of the main reasons to the have an infinitely extending three-dimensional frameworks of alumina and silica tetrahedra [7]. Each of the $\mathrm{AlO}_{4}$ and $\mathrm{SiO}_{4}$ are linked together by sharing an oxygen atom to form $n$-rings, cages, cavities, and channels, where the molecular sieve properties are exhibited. As a molecular sieve, a typical zeolite contains millions of uniform size and regular shaped pores, which specific molecules can go in and out. This particular structure makes it a very favorable material in certain industries.

Even since large-scale production of zeolites was invented, zeolites have been employed in variety of applications, and the most famous one, in terms of energy 


\section{Nanomedicine \& Nanotechnology Open Access}

application, is petroleum refining. Zeolites are involved in many important processes in refining, such as fluid catalytic cracking (a process to convert gasoil into gasoline), reforming (a process to crack heavy naphtha into small aromatic compounds), and hydrocracking (a process to transform less0valuable and heavier fractions into lighter hydrocarbons [8]. Most of the time, zeolites are playing a catalyst role to promote the entire reaction.

However, petroleum is a non-renewable source of energy and it is going to run out of its stocks in the coming future, thus, alternatives must be contrived. In the following sections, we will introduce the role of zeolites in the field of biofuels and fuel cells, as substitutes for petroleum.

\section{Review of Molecular Sieve}

Molecular sieve property was first demonstrated by Weigel and Steinhof in 1925, and termed and described in James W. McBain's publication, "The Sorption of Gases and Vapours by Solids", in 1932 [5]. The sieves are solid with three-dimensional framework of tetrahedral oxygen atoms that contains millions of uniform size and regular shaped pores. The pores are in the same diameter normally range from 3 to 10 Angstorm $(\AA)$. They act as sieves on a molecular scale as they selectively absorb molecules that fit into their pore size and exclude those that are too large [9]. They are different from filters as they operate on a molecular level and trap the absorbed molecules instead of blocking the them. Examples of molecular sieves are zeolites, active carbon, porous glass and silicon oxides. Due to their sieve property, they have been widely applied in areas such as absorbents, gas separations, laundry detergents, oil refinery and petrochemical industries, and even health aspect [10-13].

\section{Historical Background of Zeolite}

In 1756, a Swedish mineralogist, Axel Fredick Cronstedt (1722-1765), published a paper title "Rön och Beskrifning Om en oberkant bärg art, som kallas Zeolites" on the Journal of the Swedish Royal Academy of Science [6]. In his paper, he introduced a brand-new type of material. Thus, he coined it the term "zeolite", which is a combination of two Greek words, 'zeo' and 'lithos' meaning 'to boil' and 'stone' as these minerals were observed to have 'boiling' properties and steam was formed from the pores when heated in a blow pipeflame. Two years later, Cronstedt published his views on mineral classification by chemical compositions instead of physical properties and introduced the mineralogical classification of zeolite in his "An Essay Towards a System of Mineralogy" [5]. Thus, based on this morphological classification, the first discovered zeolite mineral in human history, Cronstedt's zeolite, was widely reported as stilbite not until very recent to be investigated as stellerite [6] (Figure 1).

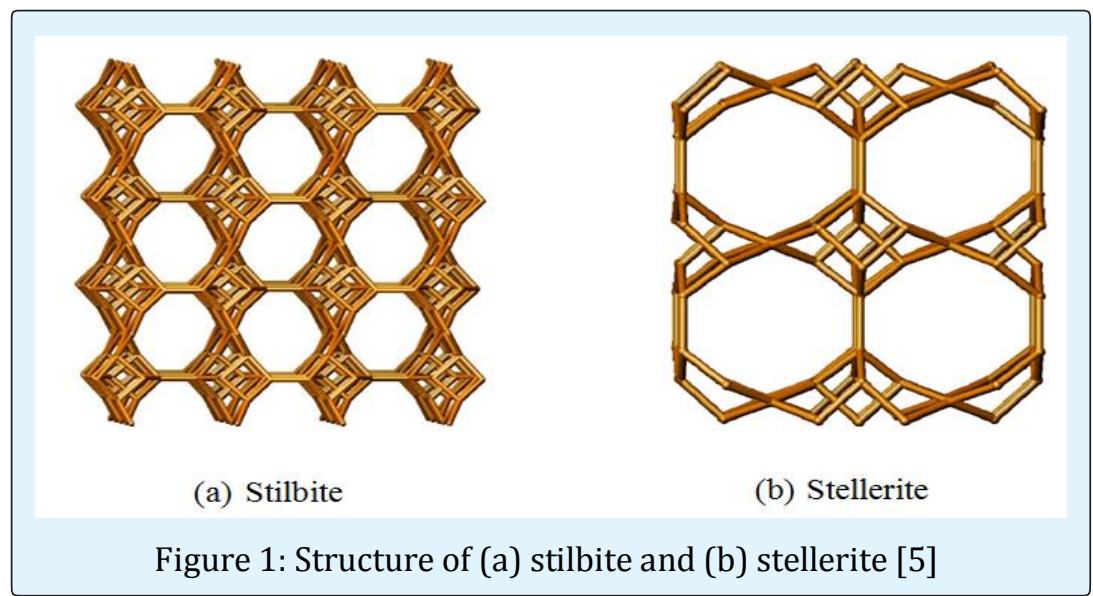

Due to its rarity, zeolites chemistry was paused for almost 200 years ever since Cronstedt's first publication. Only limited amount of large natural zeolites ( $\mathrm{mm}$ to $\mathrm{cm}$ in size) that could be isolated from basaltic rocks were accessible. Therefore, zeolites remained primarily laboratory purposes [5]. Until late 1930-1940s, a New Zealand chemist, Richard Barrer, recognized the necessity of having synthetic zeolite so that the development of large-scale industrial process using zeolite would not be limited by its rarity. So he started his research on preparing synthetic zeolite by reacting known chemicals, such as analcite or leucite or precipitated alimonosilicates, with concentrates solutions of barium or potassium salts at high temperature and autogenous pressure [14]. He successfully produced the first synthetic zeolite with no known natural counterpart [5] that is the chabazite 


\section{Nanomedicine \& Nanotechnology Open Access}

analogue ZK-5. Greatly influenced by Barrer's works, Bob Milton synthesized another two specimen of zeolites A and X in 1950. Barrer's and Milton's contribution to synthetic zeolite industry had laid the cornerstone of zeolite technology for today (Figure 2).

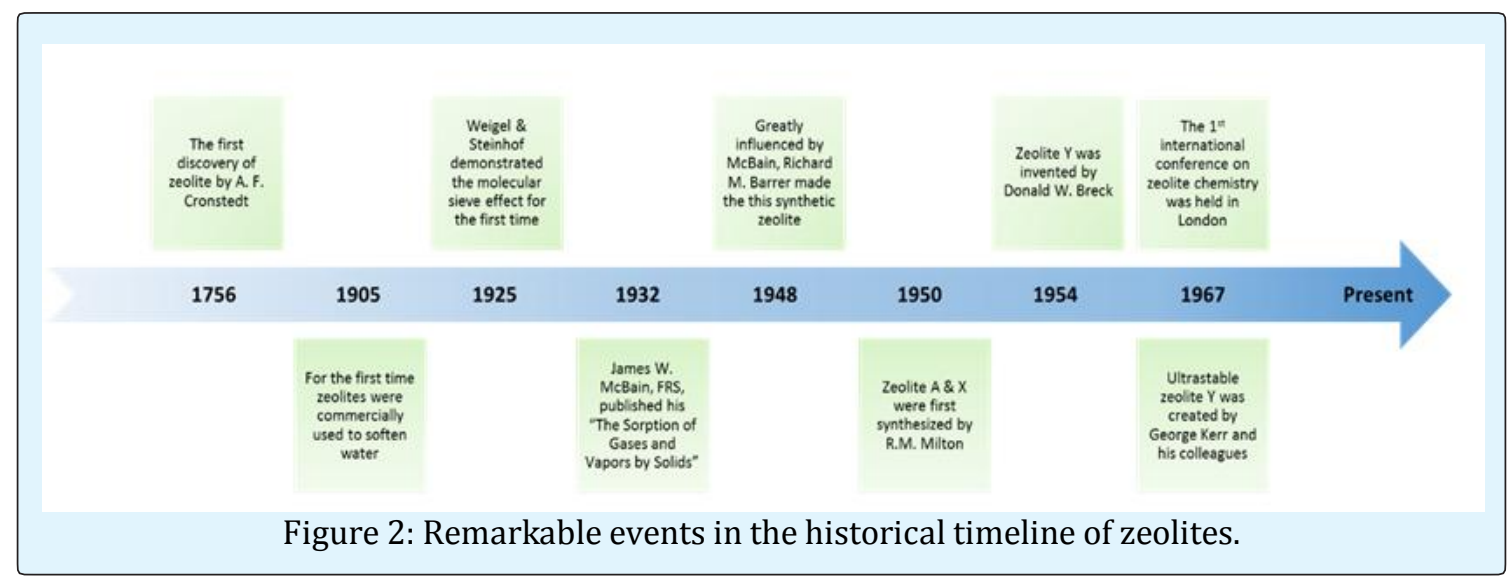

\section{Structure of Zeolite}

It is important for us to understand the structures and frameworks of zeolites as they are highly related to the properties of zeolites, such as selectivity in ion exchange, sorption capacity, thermostability, reversibility in hydration and dehydration, etc. According to W. M. Meier, one of the very first scientist who classified zeolites by framework type [15], for most of the zeolites, they can be generalized with a formula:

$$
M_{m / z}\left[\mathrm{mAlO}_{2} \cdot n \mathrm{SiO}_{2}\right] \cdot q \mathrm{H}_{2} \mathrm{O}
$$

where $\mathrm{z}$ is the valency of the exchangeable metal cation $M$ which balance the negative charges of the entire aluminosilicate framework [17]. However, the latest general formula adopted by the Structure Commission of the International Zeolite Association (IZA) is expressed in the following:

$$
\left|M_{x}\left(H_{2} O\right)_{\gamma}\right|\left[A l_{x} S i_{(t-x)} O_{2 t}\right]-\boldsymbol{I Z} \boldsymbol{A}
$$

This formula means that, in a unit cell of this zeolite, the framework contains $\chi$ number of aluminate $\left[\mathrm{AlO}_{4 / 2}\right]$, $(t-\chi)$ number of silicate tetrahedra $\left[\mathrm{SiO}_{4 / 2}\right]$, where $t$ is the total number of tetrahedral atoms within the framework of a unit cell. $M$ represents the exchangeable metal cation for negative charge balance and $\gamma$ is the number of adsorbed water molecules in cavities [18]. Symbols enclosed in the | | blanket represent the guest species while bolded blanket, [ ], represents the host framework. IZA refers to the three-letter code assigned by the IZA regarding the framework type of the zeolite [7].
Typically, zeolites have a three-dimensional, fourconnected framework of $\mathrm{TO}_{4}$ tetrahedron, where $\mathrm{T}$ refers to a cation ( $\mathrm{Si}, \mathrm{Al}, \mathrm{P}, \mathrm{Ga}, \mathrm{Ge} \mathrm{B}, \mathrm{Be}$, etc.) $[7,19]$. This $\mathrm{TO}_{4}$ is a basic building unit (BBU) in a zeolite and they are linked to each other by sharing a corner oxygen atom. When several BBUs are connected, they become composite building units (CBU) [7]. There are also secondary building units (SBUs) which contains $16 \mathrm{~T}$-atoms or above and are invariably non-chiral [19].

A zeolite structure can be described separately in its framework type and framework structure. The framework type of a zeolite simply refers to the connectivity (topology) of the tetrahedrons in its most ideal and highest possible symmetry [19] while the framework structure includes composition of framework, extraoframework cations, structural defects, etc [15].

According to the rules given by an IUPAC Commission on Zeolite Nomenclature in 1986 [19], a three-letter code, such as LTA (from Linde Type A), DOH (from Dodecasil 1H), FAU (from Faujasite), will be assigned to all zeolites based on their corresponding framework type by the IZA. All the codes are derived from the name of the Type Materials and must be written in bold letter. Details of the codes are available in the 'Framework Type Data Sheets' given by the 'Atlas of Zeolite Framework Types' published on behalf of the IZA.

Sometimes it is more convenient to discuss the zeolite framework type in terms of their structural features, like composite building units (CBUs), chains, cages, channels, and sheets, as many zeolites may share the same. 


\section{Nanomedicine \& Nanotechnology Open Access}

As aforementioned, a CBU is formed from joining a number of BBUs and the simplest form of CBUs are rings, which is denoted as $n$-ring ( $n$ is the number of tetrahedra contained in a ring) [18]. It is essential the recognize the $n$-ring as it determines the size of the pore openings. The smaller the $n$ is, the smaller the pore opening is. Typically, CBUs are displayed in three-letter codes, for examples $d 4 r$ or lau, and the pore opening is expressed in terms of free diameters or effective pore width $(\AA)$.

As another form of CBUs, cage refers to those polyhedral building units that water molecules are not allowed to pass through as the pore opening is too small even for the largest ring [18]. The cage is normally expressed in terms of the number of surface they have. For instance, a cubic cage is written in [46], and a cage with six 4-rings as well as two 6-rings is written as $\left[4^{6} 6^{2}\right]$ [15].

Apart from cages, cavities, channels, and framework density are also considered as characteristics of zeolite framework type. Cavities are very similar to cages, however, molecules are allowed to get in and out of the cavity [18]. Channels are formed by many $n$-rings linked together in a tube-shaped that extend infinitely in at least one dimension (most likely two or three dimensions [18] and molecules can diffuse along the $n$-ring pores. Framework density simply means the number of T-atoms per $1000 \AA ̊$ [19].

In opposite to the framework type, framework structures focus on how the structure, like composition, cations, of the zeolite would influence the zeolite properties [15]. Among all aspects, zeolite framework composition appears to be the most important one as it determines the (thermo-) stability of the zeolite.

Here we focus on the application of zeolite in energy aspect, readers who are interested in the structure of zeolite could refer to 'Atlas of Zeolite Framework Types 'and 'Introduction to Zeolite Science and Practice'.

\section{Zeolite in Biofuel Production}

The consumption of petroleum and other fuels (including NGPL, biofuels, CTL, GTL, kerogen and refinery gain) remains ascending as reported in the International Energy Outlook 2016 (IEO2016) Reference case [20]. Despite the slow economic growth and static or declining population levels of Organization for Economic Cooperation and Development (OECD) - which is a group of 34 member countries- there still exists a net increase of 0.6 million barrels per day $(\mathrm{b} / \mathrm{d})$ of fuels consumption in
2040, compared to 2012. The total fuels consumption by non-OECD broke even with OECD in 2013 and will rise to 75 million b/d (Figure 3).

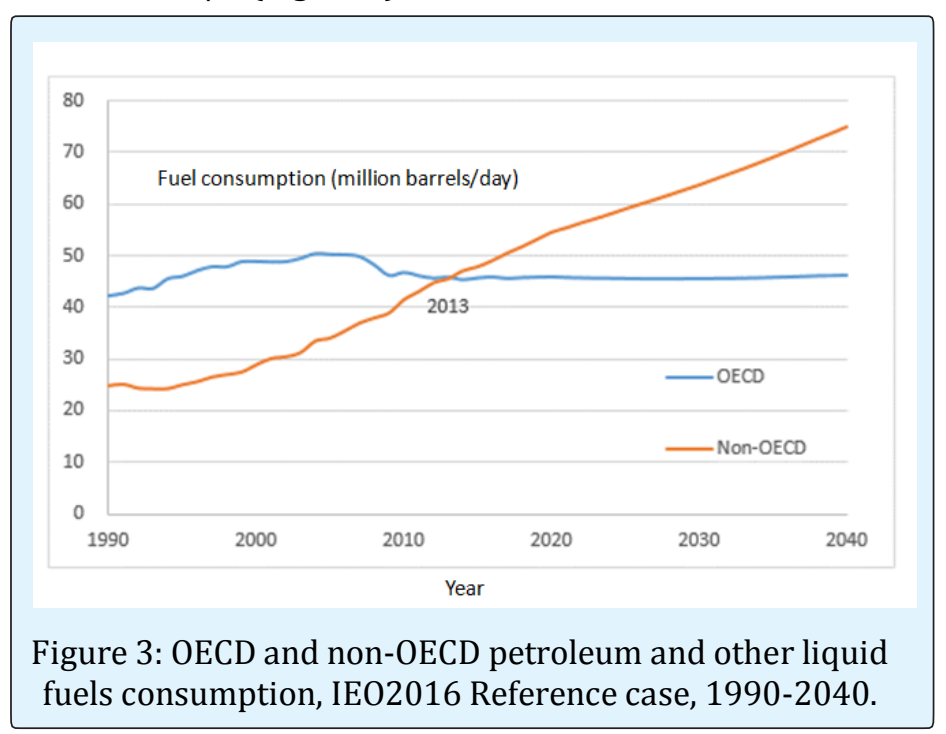

Biofuels account for the second largest component of other liquid fuel. Biofuel is a collective term for renewable liquid or gas fuels, including ethanol and biodiesel that generated from biomass [21]. A five-fold increase in biofuel production was recorded in US from 2002 to 2013 [22]. In fact, the fuels consumption is expected to growth exponentially in the future, especially for the other fuel types due to a few reasons. Unlike fossil fuels, biofuel generated from biomass is theoretically inexhaustible. It does not take millions of years for feedstocks to be replenished or rejuvenated. Yet, restrictive legislations and regulations are the main driving forces on the increasing trend on biofuels consumption and supply. As stated in the Energy Independence and Security Act of 2007 (EISA), 36 billion gallons of renewable fuel, in which a certain percentage must be advanced biofuel, shall be blended into domestic transportation fuels each year by 2022 [23].

Theoretically, biofuels are converted from biofuel feedstocks, such as agricultural crops (e.g. corn, soy, vegetable oil), animal by-products (e.g. animal fats), plant materials (e.g. wood, wool), and recycled waste (e.g. waste cooking oil, grease). On average, around $60 \%$ of energy derived from feedstocks can be transformed to deliverable biofuels while the rest are energy losses or co-products [22]. Currently, soybean oil, corn oil, canola oil and palm oil are the majority feedstocks for biofuels production as reported by the U.S. Energy Information Administration (EIA) in 2013. 


\section{Nanomedicine \& Nanotechnology Open Access}

Liquid biofuels can be separated into two categories: the first-generation or conventional biofuel and the secondgeneration biofuel. The first-generation biofuels are mostly made from arable crops in which sugar, starch or vegetable oil. Oil could be easily extracted from these materials using conventional methods. However, their limitations and drawbacks gradually emerge. For examples, they are limited in the ability of greenhouse gases reduction (except for sugarcane ethanol), they could possibly create needless competition on land and water used for food production, and their production cost is high [24]. With growing concerns in the above impacts, many turn their interests in developing second-generation biofuels that could avoid the problems. The secondgeneration biofuels are produced from non-edible biomass, namely lignocellulosic biomass, agricultural resides or waste. In comparison, the second-generation biofuels are expected to be much more superior than the first-generation, in terms of climate change mitigation, competition of food, water and land.

Biofuels produced from biomass is cleaner and greener choice compare to the fossil fuels. It could be a solution to the negative impacts raised by using fossil fuels in the foreseeable future. The reason they still have not yet taken up the market mainly due to immature production technologies. Homogeneous catalysts are commonly used in the biofuels production processes, such as transesterification and hydrolysis process. But many researchers started eyeing on replacement of homogeneous catalysts to heterogeneous catalysts (solid catalysts) owning to the serious drawbacks they have, namely handling hazards, soap formation, separation difficulty and toxic waste production $[25,26]$. In such case, zeolites could possibly be a feasible choice.

\section{First-Generation Biofuels}

Sugar and vegetable oil are two main sources of firstgeneration biofuels, since they relatively common and easy to be extracted. The extraction process like pyrolysis, gasification, transesterification and hydrolysis always involves the use of catalysts. In this section, we will show some examples or applications of zeolites as catalysts on first-generation biofuels production.

Sugar is a general name for sweet tasted soluble carbohydrates and one of the major types of carbohydrates found in food. There are several types of sugar and monosaccharides (e.g. glucose, fructose), disaccharides (e.g. sucrose, maltose) and polysaccharides (e.g. starch, cellulose) are the three main types. It is one of the major feedstocks available for the first-generation biofuels production as carbohydrates occupy for $75 \%$ of annually renewable biomass approximately. It is also a key intermediate for converting biomass to fuel oils [26].

Starch is another major types of carbohydrates and is a polysaccharide that composites of glucoses units linked by glycosidic bonds. Amylose is the branchless form of starch which means there the sugar molecules do not branch off from the main chain while amylopectin is the branched form of starch. Native starch molecules normally consist of $20 \%$ amylose and the rest are amylopectin [27].

Back in 1990, a patent was issued to Jacobs $\mathrm{P}$ and Hinnekens $\mathrm{H}$ for their invention in single step conversion of polysaccharides to polyhydric alcohols [28] which could be one kind of biofuel. Corn starch was put into a Parr reaction for hydrolysis and hydrogenation under high temperature (around $130-180^{\circ} \mathrm{C}$ ) and high pressure (5.52 $\mathrm{MPa}$ ) for around 0.5-1 hour with the presence of zeolite HUSY, Ru on acid ultrastable Y zeolite - as catalyst. Zeolite NaY LZY-52 powder was the initial material for HUSY. The powder first underwent ion-exchange with $\mathrm{NH}_{4} \mathrm{Cl}$ solution and washed until $\mathrm{Cl}$-free for further calcination for 12 hours. The above steps were repeated three times until sodium-free material is obtained. The HUSY contained 3\% of Ru was obtained by final ion-exchange with Rusolution. $99 \%$ mole alditols was obtained for the reaction operated at $180^{\circ} \mathrm{C}$ with $25 \% \mathrm{w} / \mathrm{w}$ of starch in water for $0.58 \mathrm{~h}$. The results also demonstrated that higher mole percentage could be achieved for longer reaction time, however, this will take unreasonable long time for achieving $100 \%$ mole alditols which is not cost-effective. The HUSY was also tested with sucrose and lactose and this further confirmed that the process was not only applicable for hydrolyzing polysaccharide, also for disaccharides to their basic monosaccharide. H-Mordenite and HZSM-5 prepared from ZSM-5 were also employed and gave similar results as HUSY but higher conversion rate of hexitols.

It is known that typical solid acid catalysts include zeolites are easily poisoned during the hydrolysis process while water is used as solvent or reaction media, thus could not be recycled afterwards due to leaching of acid groups [26]. Dhepe P, et al. proposed to modify mesoporous silicas, HMM-1, with sulfonic acid to produce a recyclable water-tolerant solid acid catalyst for hydrolysis of disaccharide and polysaccharide, i.e. sucrose and starch, to glucose and fructose. Experimental results showed that the water-tolerant solid acid catalysts yield more monosaccharides than conventional catalysts like Amberlyst-15, Nafion-silica and HZSM-5, and no decrease in catalytic activity or leaching or acid groups or blocking 


\section{Nanomedicine \& Nanotechnology Open Access}

or pore sites were observed. In another word, these water-tolerant solid acid catalysts have higher conversion rate and turnover frequency [24].

After hydrolysis and hydrogenation, the obtained monosaccharides can be further converted into useful diesel and fuel derivatives such as hydrocarbons and oxygenated additives through esterification and hydrogenation [24].

There is also example of commercialized biofuel production process using zeolites as catalysts. A novel catalytic conversion technology of carbohydrates to hydrocarbon - BioForming® process - was developed and patented by Virent, Inc. It employs the Aqueous Phase Reforming (APR) technology together with modified conventional catalytic processing, in which modified ZSM5 is used as catalysts, to transform sugar into liquid fuels, such as gasoline, jet fuel and diesel that match petroleum fuels' compositions, functions and performance, and chemicals [29]. One distinct advantage is that the BioForming $®$ process has high feedstock flexibility, nonfood feedstocks like lignin, cellulose and hemicellulose can also be processed. A brief summary of the industrial process is illustrated in Figure 4.

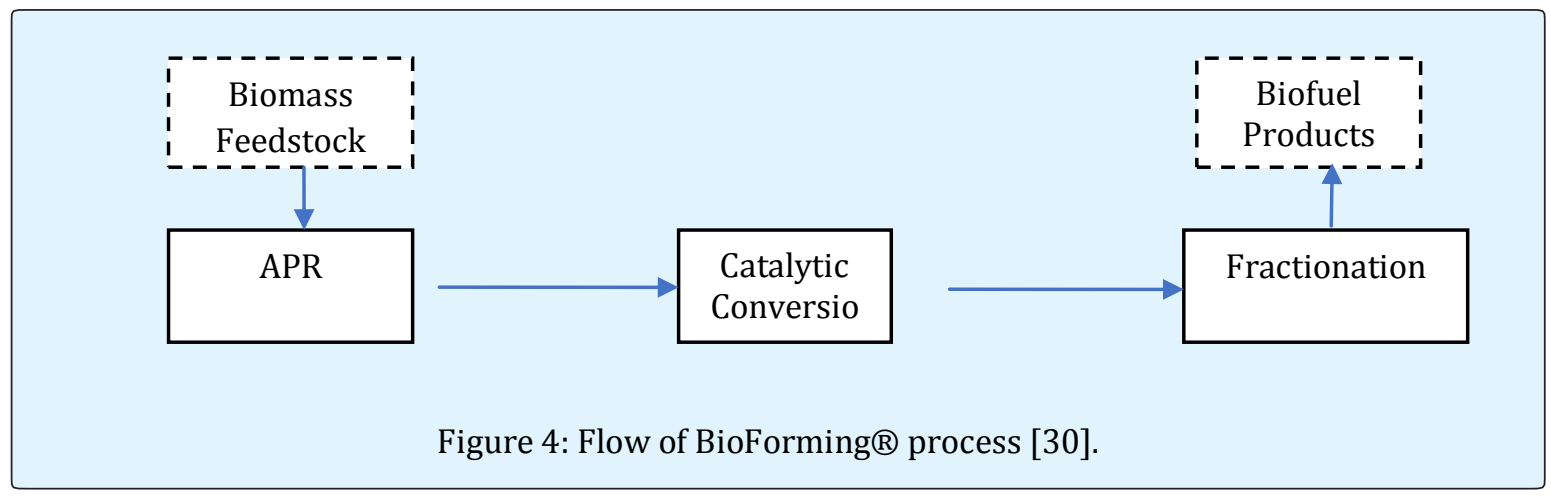

On the other hand, vegetable oils, triglyceride esters extracted from plants, are also a common feedstock for biofuel production. Theoretically, these oils could be used directly as substitutes for diesels since they are high in energy content. They have not been injected directly into diesels engines, despite their advantages, mainly due to their high viscosity.

Fatty acid methyl ester (FAME), which is produced from transesterification of triglycerides with methanol and catalysts [24], is one of the major component presented in biodiesel. As mentioned before, homogeneous catalysts are mostly employed in the processes, leading to several unfavorable drawbacks. To avoid those drawbacks, heterogeneous catalysts have been extensively studied in many literatures [31-34].

Lopez et al. compared a list of homogeneous and heterogeneous catalysts on the performance of transesterification of triacetin, as a model of larger molecules of triglycerides that can be found in animal fats and vegetable oils, together with methanol [35]. The list of catalysts that they used is shown in Table 1 . All the reactions took place at $60^{\circ} \mathrm{C}$ in a parr reactor and 6:1 anhydrous methanol to triacetin ratio with $2,0.5$ and
0.025 wt. \% for solid catalysts, $\mathrm{H}_{2} \mathrm{SO}_{4}$ and $\mathrm{NaOH}$ respectively. Results shown that homogenous catalysts are more active than heterogeneous catalysts and basic catalysts have higher conversion rate than acidic catalysts. However, the basic ETS-10 (Na, K) also shown promising result where $99 \%$ of traincetin conversion was achieved in 8 hours, very comparable to $\mathrm{NaOH}$.

\begin{tabular}{|c|c|}
\hline Catalyst & Type \\
\hline \multicolumn{2}{|l|}{ Acids } \\
\hline Amberlyst-15 & Solid \\
\hline ETS-10 (H) & Solid \\
\hline $\mathrm{H}_{2} \mathrm{SO}_{4}$ & Liquid \\
\hline Nafion NR50 & Solid \\
\hline Sulfated Zirconia (SZ) & Solid \\
\hline Supported Phosphoric Acid (SPA) & Solid \\
\hline Tungstated Zirconia (WZ) & Solid \\
\hline Zeolite H-Beta & Solid \\
\hline \multicolumn{2}{|l|}{ Bases } \\
\hline ETS-10 $(\mathrm{Na}, \mathrm{K})$ & Solid \\
\hline $\mathrm{MgO}$ & Solid \\
\hline $\mathrm{NaOH}$ & Liquid \\
\hline
\end{tabular}

Table 1: List of acidic and basic catalysts. 


\section{Nanomedicine \& Nanotechnology Open Access}

\section{Second-Generation Biofuel}

Second-generation biofuels are produced from nonedible biomass, mostly from lignocellulose. Lignocellulose is the most abundantly feedstocks for biofuel production and can be classified into three different groups: virgin biomass, waste biomass and energy crops. Among the sectors, the energy crops refer to crops that have high yield and can be densely planted, and serve as major feedstocks for second-generation biofuels. Lignocellulose composites of cellulose, hemicellulose and lignin and they can be transformed to biofuels by applying different methods.

Cellulose, which is insoluble in water, is linear polysaccharide with $\beta$-D-glucose as its basic units. It can be transformed easily into its glucose units chemically. A. Onda et al. studied the performance of different zeolites on selective hydrolysis of cellulose into glucose [36]. Several H-form zeolites, such as H-beta zeolites with Si/Al $=12$ and 75, $\mathrm{H}$-mordenite with $\mathrm{Si} / \mathrm{Al}=10$ and $\mathrm{H}-\mathrm{ZSM} 5$ with $\mathrm{Si} / \mathrm{Al}=45$, were tested in an autoclave at $150^{\circ} \mathrm{C}$ for 24 hours with agitation (22 rpm). H-ZSM5 and H-beta with $\mathrm{Si} / \mathrm{Al}=75$ found to have higher yield for glucose than $\mathrm{H}$-beta with $\mathrm{Si} / \mathrm{Al}=12$ and $\mathrm{H}$-mordenite. They suggested that the higher Si/Al ratio would result in higher hydrophobic character which cause the organic products (glucose) more favorable than water. However, cellulose fibers are surrounded by hemicellulose and lignin fibers (Figure 5), and pulping process is normally applied to separate them from hemicellulose and lignin [24].

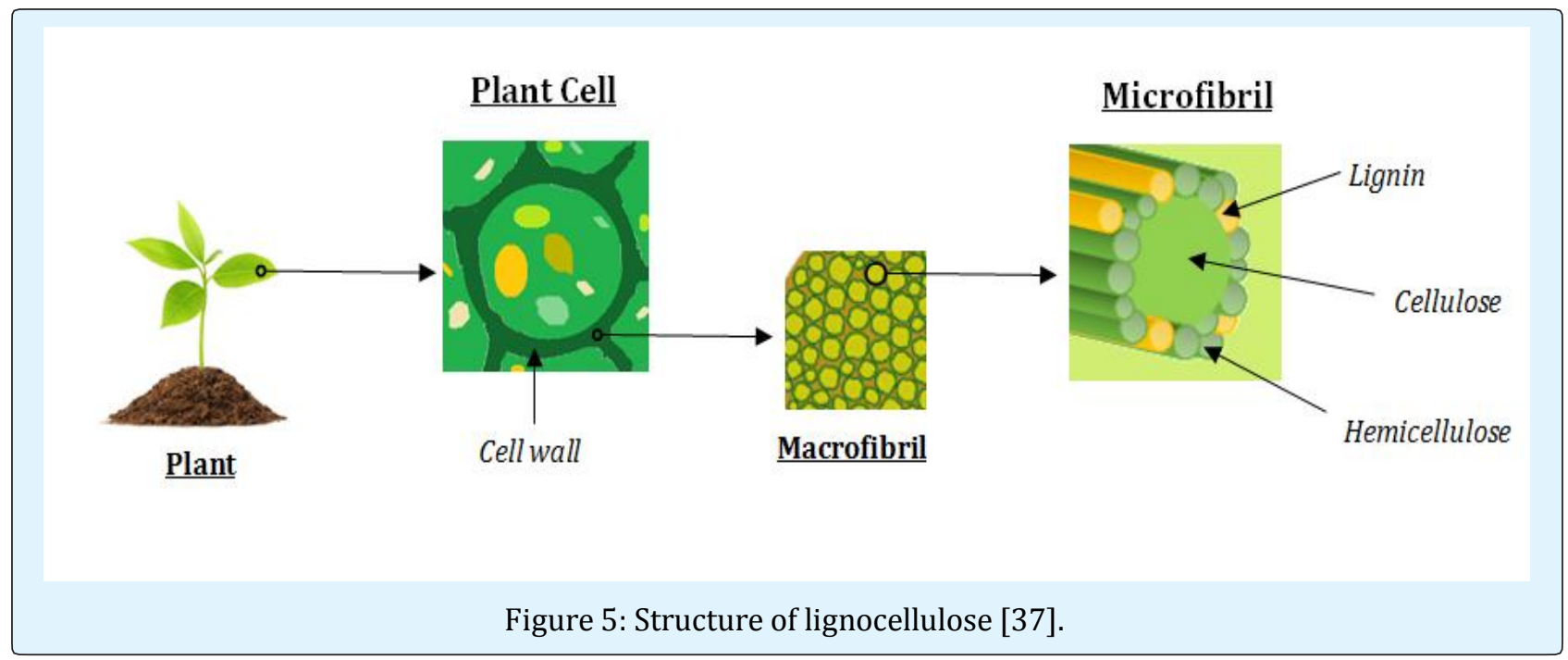

The remaining hemicellulose and lignin can be treated to further produce sugars and phenol.

Hierarchical HUSY zeolite was suggested to be an effective catalyst for the hydrolysis of hemicellulose to total reduced sugars (TRS) by Zhou L, et al. [38]. The Hierarchical HUSY zeolites were reacted with hardwood (as a model of derived hemicelluloses) in an autoclave reactor.

Among all species tested, zeolites with larger external surface area and lower acidity yielded higher in total reduced sugars (TRS), and the optimal conditions for maximum yield of TRS was found to be $2 / 1$ catalyst to hemicellulose ratio under $140^{\circ} \mathrm{C}$ for 6 hours (Figure 6). In order to obtain a higher TRS yield, a supplementary research was conducted to study the performance of sulfonated hierarchical HUSY zeolite [39]. Similar experiment approaches were adopted and yielded $78 \%$ for TRS which is much higher to that obtained previously with hierarchical HUSY. 


\section{Nanomedicine \& Nanotechnology Open Access}

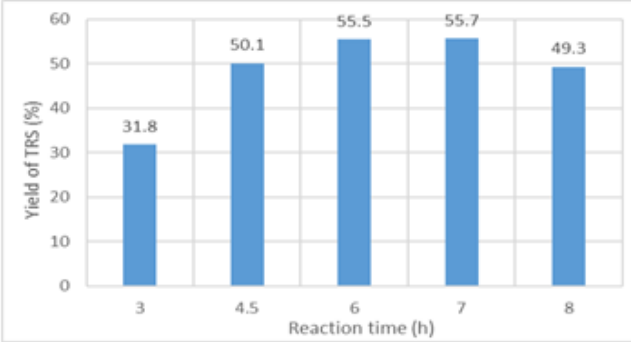

(a)

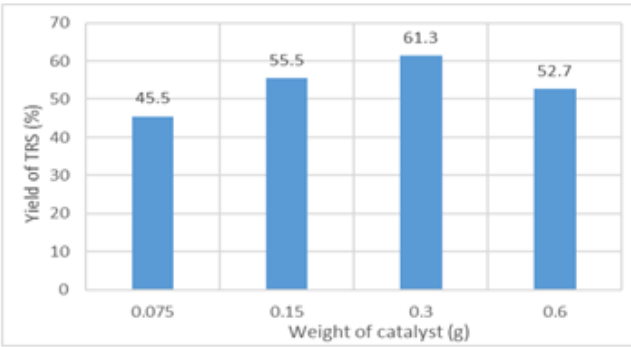

(c)

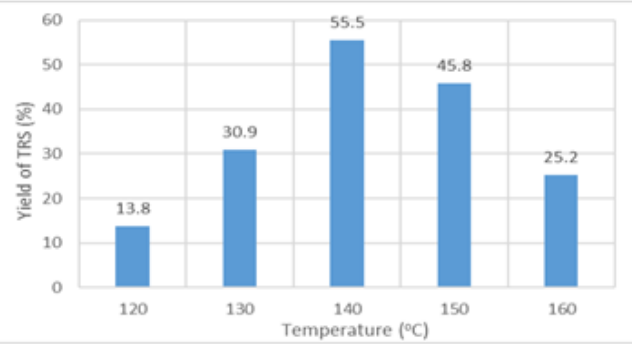

(b)

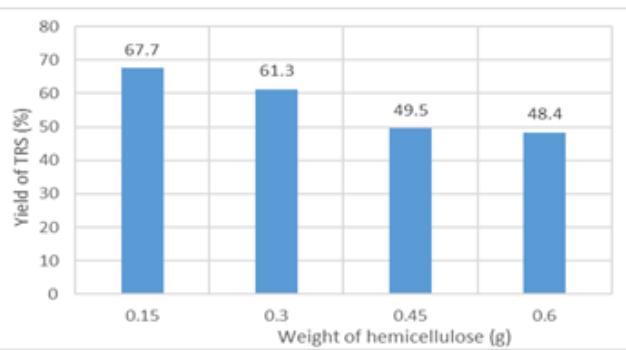

(d)

Figure 6: Yield of TRS versus (a) the reaction time at $140^{\circ} \mathrm{C}$ with $0.15 \mathrm{~g}$ catalyst and $0.3 \mathrm{~g}$ hemicellulose, (b) the temperature with $0.15 \mathrm{~g}$ catalyst and $0.3 \mathrm{~g}$ hemicellulose for $6 \mathrm{~h},(\mathrm{c})$ the weight of catalyst at $140^{\circ} \mathrm{C}$ with $0.3 \mathrm{~g}$ hemicellulose for $6 \mathrm{~h}$, and (d) the weight of hemicelluloseat $140^{\circ} \mathrm{C}$ with $0.3 \mathrm{~g}$ catalyst for $6 \mathrm{~h}$.

Several patents are owned by UOP LLC for transforming lignin into useful biofuel products [40-42], for instance, phenol, benzene, gasoline, etc. A two-stage process, depolymerization and hydroprocessing, can be applied to transform lignin into hydrocarbon gasoline, mainly nalphthenic compounds, with the presence of catalysts for which Ni-Mo are supported on zeolites [41].

\section{Zeolite in Direct Methanol Fuel Cell}

Fuel cells are electrochemical devices that convert chemical energy into electrical energy. They are becoming more and more popular since they have wide variety of applications, high specific and volumetric energy densities, and are relatively clean in which they produce electricity without combustion and pollution. Unlike batteries, electricity production is sustainable as long as source of fuel and air or oxygen are continuously supplied.

Direct Methanol Fuel Cell (DMFCs) is one kind of fuel cells that provide power for portable electronics. It is one of the most attractive power source as it is relatively clean, simple to operate, and very dense in energy. Methanol is used as the fuel at the anode and oxidize to form carbon dioxide on a catalyst layer. Protons are produced from the oxidation and pass through the proton exchange layer to form water with oxygen. The reaction mechanisms are shown in Table 2.

\begin{tabular}{|c|c|c|}
\hline Anode & Oxidation & $\mathrm{CH}_{3} \mathrm{OH}+\mathrm{H}_{2} \mathrm{O} \rightarrow 6 \mathrm{H}^{+}+6 \mathrm{e}^{-}+\mathrm{CO}_{2}$ \\
\hline Cathode & Reduction & $\frac{3}{2} \mathrm{O}_{2}+6 \mathrm{H}^{+}+6 \mathrm{e}^{-} \rightarrow 3 \mathrm{H}_{2} \mathrm{O}$ \\
\hline Overall & & $\mathrm{CH}_{3} \mathrm{OH}+\frac{3}{2} \mathrm{O}_{2} \rightarrow 2 \mathrm{H}_{2} \mathrm{O}+\mathrm{CO}_{2}$ \\
\hline
\end{tabular}

Table 2: Redox reaction mechanism of DMFC.

Nafion is a common choice of material for proton exchange membrane due to its high proton conductivity and excellent chemical stability. However, it has a few limitations that restrict the performance and efficiency of the fuel cell, namely methanol crossover (high methanol permeability), low proton conductivity at above $90^{\circ} \mathrm{C}$, and catalyst poisoning $[43,44]$. In order to combat these problems, many studies suggested to modify the Nafion membrane by addition of a variety of compounds, both organic and inorganic, onto the surface. Zeolites are one of the materials that many researchers are focused on due to their meso-/mirco-porous, stable, chemically and electronic conductivity inert properties [45].

Tricoli V and Nannetti F attempted to embed zeolites, 


\section{Nanomedicine \& Nanotechnology Open Access}

chabazite $(\mathrm{ZS} 500 \mathrm{H})$ and clinoptilolite $\left(\mathrm{ZS}_{4} \mathrm{O}_{3} \mathrm{H}\right)$, onto the Nafion in the presence of denaturated ethanol and dimethylformamide (DMF) to form either $\mathrm{H}^{+}$form or $\mathrm{Na}^{+}$ form of chabazite-nafion and clinoptilolite-nafion respectively [46]. The testes on the characteristics of the composite membrane were conducted in $22^{\circ} \mathrm{C}$ and $60^{\circ} \mathrm{C}$. Unfortunately, the composite membranes only showed significant change in proton conductivity but no notable change in methanol permeability with respect to zeolitefree Nafion.

Another zeolite/Fation composite membrane which has better performance under high operating temperature was raised by. Jung $\mathrm{DH}$, et al. [47]. Nafion/montmorillonite (MMT) nanocomposite membranes (both $\mathrm{H}^{+}$and $\mathrm{Na}^{+}$form) were produced by direct melt intercalation of Nafion into the montmorillonite and modified montmorillonite (m-MMT) synthesized from cation exchange with dodecylamine respectively.

The manufactured membranes were proven that they have better performance for high temperature operating conditions $\left(90-110^{\circ} \mathrm{C}, 125^{\circ} \mathrm{C}\right)$ compare to normal Nafion membrane. But results showed that the proton conductivity for both nanocomposite membrane species were lower than that of normal Nafion membrane, and only slightly improvement in methanol permeability.

While others devoting on developing new composite membranes, Byun SC, et al. suggested the methanol permeability could be attributed to the size of the zeolite within the membranes by comparing the methanol permeability performance of a few zeolite/Nafion membranes with different zeolite contents [48]. In general, the higher the zeolite content, the higher the methanol permeability, since methanol can leak through the void fraction between large zeolite crystals and Nafion. Nevertheless, high boiling point solvent, dimethylformamide (DMF), showed lower methanol permeability than low boiling point solvent, propanol, as a solvent in fabrication of composite membrane due to higher mechanical strength when the hydroplilic parts of both Nafion and zeolite particles are more closely packed together in the presence of high boiling point solvents.

With the discovery on the solvents effect, many attempted to functionalize the zeolite/Nafion composite membranes with solvents, such as acids and organics $[44,49,50]$.
A Nafion/acid functionalized zeolite Beta (NAFB) nanocomposite membrane with significant decrease in average methanol permeability, compared to Nafion 115, was developed by Chen $\mathrm{Z}$, et al., using concentrated $\mathrm{H}_{2} \mathrm{SO}_{4}$ [44]. Another functionalized zeolite/Nafion composite membrane was invented by Li X, et al. by grafting organic chains onto the surface of zeolite A-Nafion composite membrane using silane-based coupling agents, and decrease in methanol permeability was also noticed (compared to Nafion 117) [49]. Miserably, both of them were found to have obtrusive loss in proton conductivity $[44,49]$.

Efforts have been made to study the effects of acid strength, pore size and dimensionality, on the proton conductivity of acid-functionalized zeolites (zeolite beta, MCM-41, MCM-48) [45]. The proton conductivity decreases as follows: aryl sulfonic acid functionalized materials (S-PE-) > propyl sulfonic acid functionalized materials (S-MP-) > phosphonic acid functionalized materials (P-) $>$ carboxylic acid functionalized materials $(\mathrm{C}-)>$ oleum treated materials $(\mathrm{O}-)>$ unfunctionalized pure materials.

This trend agrees with the corresponding acid strength. Zeolite beta materials have the hydrophobic nature of nearly hydroxyl-defect-free framework, causing less complete hydrogen bonding water framework, which makes it exhibit the lowest proton conductivity. Meanwhile, MCM-48 showed highest performance on proton conductivity, probably due to its three-dimensional interconnected pore structure that reduces the electric resistance.

Instead of composite membrane, zeolites can also play as the role of anode in the DMFCs. Frinz FB, Gur TM and Shim JH patented their invention [51], a thin film all solidstate fuel cell (one kind of DMFC), in which a zeolite was employed as the anode (Figure 7). The uniform porous property of zeolites provides excellent active sites for adsorption and chemisorption of hydrocarbons, and facilitates the incorporation of transition meatal ions during ion exchange in either liquid or solid state, hence, enhancing its electrical and catalytic properties. There are some remarkable advantages of this DMFC: (1) no methanol crossover; (2) wide variety of zeolite choice, (3) cathode does not have to be precious metal, it can be selected from a group of metallic or mixed ionic electronic conducting materials. 


\section{Nanomedicine \& Nanotechnology Open Access}

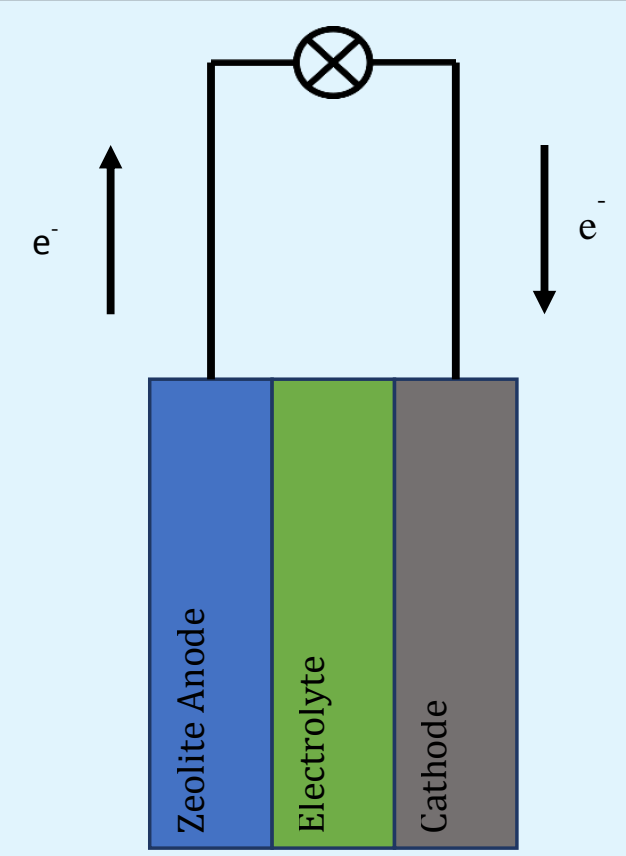

Figure 7: A thin film fuel cell using zeolite as anode.

\section{Conclusions}

This paper reviews the role of zeolites in the fields of biofuel and direct methanol fuel cell. Zeolites often act as catalysts in terms of biofuels production. Zeolite catalysts, such as HUSY and HMM-1, can help convert polysaccharides and disaccharides into monosaccharides, an intermediate which can be transformed to biofuel by esterification. The HUSY can even produce polyhydric alcohols, which could be one kind of biofuel, in single step conversion. Zeolites can also act as the support of a catalyst. Lignin can be transformed into useful biofuel products by depolymerization and hydroprocessing in the presence of zeolites supported Ni-Mo catalysts. There are also examples of zeolites being applied in commercial biofuel production process.

Apart from biofuel production, zeolites are applied in direct methanol fuel cell (DMFC) to soften the limitation of Nafion. Nafion is commonly used as the proton exchange membrane in the DMFC. However, it has several technical problems, such as methanol crossover, low proton conductivity at above $90^{\circ} \mathrm{C}$ and catalyst poisoning. Efforts have been made on studied the effects of zeolites embedded Nafion (zeolite/Nafion membrane). Results from the studies shown zeolites might be a possible solution to the future of DMFC

\section{References}

1. Zeolites Market - Global Industry Analysis, Size, Share, Trends and Forecast 2015-2023. Transparency Market Research.

2. (2015) Zeolite (Natural and Synthetic) Market for Catalysts, Adsorbents, Detergent Builders and Other Applications - Global Industry Perspective, Comprehensive Analysis, Size, Share, Growth, Segment, Trends and Forecast, 2014-2020, Market Research Store, pp: 110.

3. (2015) Zeolite Market Analysis By Product (Natural Synthetic), Application (Catalysts, Adsorbents, Detergent Builders) And Segment Forecasts To 2022. Grand View Research, pp: 105.

4. (2015) Zeolite Market Size Worth $\$ 33.80$ Billion By 2022 / Growth Rate: 2.5\%. Grand View Research.

5. Anthony F M, Thomas M (2011) Zeolites - From curiosity to cornerstone. Microporous and Mesoporous Materials 142(2-3): 423-438.

6. Colella, Gualtieri AF (2007) Cronstedt's zeolite. Microporous and Mesoporous Materials 105(3): 213221. 


\section{Nanomedicine \& Nanotechnology Open Access}

7. Broach RW (2010) Zeolite Types and Structures. Pp: 27-59.

8. Primo A, Garcia H (2014) Zeolites as catalysts in oil refining. Chem Soc Rev 43(22): 7548-7561.

9. Cejka J, Bekkum H, Corma A, Schuth F (2007) Introduction to Zeolite Molecular Sieves. Elsevier 168: 1094.

10. (1999) Cleaning Up with Chemistry: Investigating the Action of Zeolite in Laundry Detergent. J Chem Educ 76(10): 1416A.

11. Marcilly C R (2000) Where and how shape selectivity of molecular sieves operates in refining and petro chemistry catalytic processes. Topics in Catalysis 13(4): 357-366.

12. Qing MW, Dongmin S, Martin B, Miu LL, Shuguang D (2002) Metallo-organic molecular sieve for gas separation and purification. Microporous and Mesoporous Materials 55(2): 217-230.

13. Lin WG, Zhou Y, Cao Y, Zhu JH (2013) Applying heterogeneous catalysis to health care: In situ elimination of tobacco-specific nitrosamines (TSNAs) in smoke by molecular sieves. Catalysis Today 212: 52-61.

14. Vaughan DEW (2007) Contributions of R. M. Barrer to zeolite synthesis. Studies in Surface Science and Catalysis 170: 87-95.

15. McCusker LB, Baerlocher C (2007) Zeolite structures. 168: 13-37.

16. Meier W (1986) Zeolites and zeolite-like materials. Studies in Surface Science and Catalysis 28: 13-22.

17. Zeolites. Everyscience.com

18. Auerbach SM, Carrado KA, Dutta PK (2003) Handbook of Zeolite Science and Technology, CRC Press, pp: 1204.

19. Baerlocher C, McCusker LB, Olson DH (2007) Atlas of Zeolite Framework Types, Elsevier.

20. (2016) International Energy Outlook. US Energy Information Administration, Washington (2012) Biofuels Issues and Trends. US Energy Information Administration, Washington.
21. Joyce M (2016) Biofuels production drives growth in overall biomass energy use over past decade. US Department of Energy.

22. Schnepf R, Yacobucci BD (2013) Renewable Fuel Standard (RFS): Overview and Issues. CRS Report for Congress.

23. Perego C, Bosetti A (2011) Biomass to fuels: The role of zeolite and mesoporous materials. Microporous and Mesoporous Materials 144(1-3): 28-39.

24. Lam MK, Lee KT, Mohamed AR (2010) Homogeneous, heterogeneous and enzymatic catalysis for transesterification of high free fatty acid oil (waste cooking oil) to biodiesel: A review. Biotechnology Advances 28(4): 500-518.

25. Dhepe PL, Ohashi M, Inagaki S, Ichikawa M, Fukuoka A (2005) Hydrolysis of sugars catalyzed by watertolerant sulfonated mesoporous silicas. Catalysis Letters 102(3): 163-169.

26. Jenkins P, Donald A (1995) The influence of amylose on starch granule structure. International Journal of Biological Macromolecules 17(6): 315-321.

27. Jacobs P, Hinnekens H (1990) Single-step catalytic process for the direct conversion of polysaccharides to polyhydric alcohols.

28. Blommel PG, Keenan GR, Rozmiarek RT, Cortright R (2008) Catalytic conversion of sugar into conventional gasoline, diesel, jet fuel, and other hydrocarbons. International Sugar Journal 110(1319): 672-679.

29. Blommel P (2011) Catalytic Conversion of Carbohydrates to Hydrocarbons.

30. Kim HJ, Kang BS, Kim MJ, Park YM, Kim DK, et al. (2004) Transesterification of vegetable oil to biodiesel using heterogeneous base catalyst. Catalysis Today 93-95(1): 315-320.

31. MacedoI CCS, Abreu FR, Tavares AP, Alves MB, Zara LF, et al. (2006) New heterogeneous metal-oxides based catalyst for vegetable oil trans-esterification. J Braz Chem Soc 17(7).

32. Chai F, Cao F, Zhai F, Chen Y, Wang X, et al. (2007) Transesterification of vegetable oil to biodiesel using a heteropolyacid solid catalyst. Advanced Synthesis Catalysis 349(7): 1057-1065. 


\section{Nanomedicine \& Nanotechnology Open Access}

33. Đokić M, Kesić Ž, Krstić J, Jovanović D, Skala D (2012) Decrease of free fatty acid content in vegetable oil using silica supported ferric sulfate catalyst. Fuel 97: 595-602.

34. López DE, Goodwin JG, Bruce DA, Lotero E (2005) Transesterification of triacetin with methanol on solid acid and base catalysts. Applied Catalysis A General 295(2): 97-105.

35. Onda A, Ochi T, Yanagisawa K (2008) Selective hydrolysis of cellulose into glucose over solid acid catalysts. Green Chemistry 10: 1033-1037.

36. Rubin EM (2008) Genomics of cellulosic biofuels. Nature 454: 841-845.

37. Zhou L, Shi M, Cai Q, Wu L, Hu X, et al. (2013) Hydrolysis of hemicellulose catalyzed by hierarchical H-USY zeolites - The role of acidity and pore structure. Microporous and Mesoporous Materials 169: 54-59.

38. Zhou L, Liu Z, Shi M, Du S, Su Y, et al. (2013) Sulfonated hierarchical H-USY zeolite for efficient hydrolysis of hemicellulose/cellulose. Carbohydr Polyme 98(1): 146-151.

39. Huibers DTA, Parkhurst HJ (1983) Lignin hydrocracking process to produce phenol and benzene.

40. Shabtai JS, Zmierczak WW, Chornet E (1999) Process for conversion of lignin to reformulated hydrocarbon gasoline.

41. Zmierczak W, Miller J (2008) Processes for catalytic conversion of lignin to liquid bio-fuels and novel biofuels.

42. Mecheri B, Felice V, Zhang Z, D’Epifanio A, Licoccia S, et al. (2012) DSC and DVS investigation of water mobility in Nafion/zeolite composite membranes for fuel cell applications. The J Phys Chem 116(39): 20820-20829.

43. Chen Z, Holmberg B, Li W, Wang X, Deng W, et al. (2006) Nafion/Zeolite Nanocomposite Membrane by in Situ Crystallization for a Direct Methanol Fuel Cell. Chemistry of Materials 18(24): 5669-5675.

44. McKeen JC, Yan YS, Davis ME (2008) Proton Conductivity of Acid-Functionalized Zeolite Beta, MCM-41, and MCM-48: Effect of Acid Strength. Chemistry of Materials 20(16): 5122-5124.

45. Tricoli V, Nannetti F (2003) Zeolite-Nafion composites as ion conducting membrane materials. Electrochimica Acta 48(18): 2625-2633.

46. Jung D, Cho S, Peck D, Shin D, Kim J (2003) Preparation and performance of a Nafion(R)/montmorillonite nanocomposite membrane for direct methanol fuel cell. Journal of Power Sources 118(1-2): 205-211.

47. Byun SC, Jeong YJ, Park JW, Kim SD, Ha HY, et al. (2006) Effect of solvent and crystal size on the selectivity of ZSM-5/Nafion composite membranes fabricated by solution-casting method. Solid State Ionics 177(37-38): 3233-3243.

48. Li X, Roberts EPL, Holmes SM, Zholobenko V (2007) Functionalized zeolite A-nafion composite membranes for direct methanol fuel cells. Solid State Ionics 178(19-20): 1248-1255.

49. Wu H, Zheng B, Zheng X, Wang J, Yuan W, et al. (2007) Surface-modified Y zeolite-filled chitosan membrane for direct methanol fuel cell. Journal of Power Sources 173(2): 842-852.

50. Prinz FB, Gür TM, Shim JH (2010) Solid-state direct methanol thin film fuel cell.

51. (2016) Structure of lignocelluloses. Nature Education.

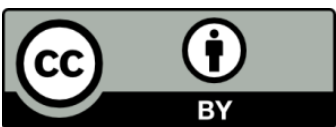

